\title{
THE USAGE OF CITRUS TREES PRUNING OUTPUTS FOR PARTICLEBOARDS PRODUCTION
}

\author{
E. A. El Saeidy*
}

\begin{abstract}
In the Egyptian agricultural context, the recent situation indicates that there decreasing tendency of the flax plantation intensity in the last decade. The cultivated area decreased from about 31.000 feddan in the year 2003 to about 3.500 feddan in the year 2013. However, this activity is still relevant in the Egyptian agricultural panorama. The flax plantation is mainly processed in the middle of Nile Delat. Village Shobra Melles belonged to El Ghrbia Governorate is considered the major cultivated area of flax. It cultivates about $75 \%$ from the flax production in Egypt. The particleboard industry in Tanta Flax and Oil Company don't become in immune to this reality. The aim of this work is to find alternative and sustainable row materials for flax woody pulp (Saas El Ketan).
\end{abstract}

\section{INTRODUCTION}

7 he flax crop considered the oldest fibre crops used by man in clothes industry. Linen textiles were found in the tombs of ancient

Egyptians before five thousand years. Flax is a winter plant; its length ranges from $50-120 \mathrm{~cm}$ and a thickness of $1.5-3 \mathrm{~mm}$ according to the environmental conditions in which the crop grows. Flax is grown in Egypt for its fibres and seeds. Its soft and long fibres used in linen textile industry as well as thick fabrics for home furnishings. From the seeds of edible oil is extracted (hot oil) and boiling oil. The last one is used in paints and varnishes industry. Oilcake is used as food for animals, milk. Pulpwood is used in wood particleboard industry, Nady and Roland (2008).

Particleboard is a high grade, composite material made from recycled wood fibres and resin. It performs better than solid wood in many areas. It is machine dried and pressed to produce dense, stable sheets.

*Lecturer of Agric. Eng., Dept. of Agric. Eng., Faculty of Agriculture, Menoufia University. Egypt. 
Covering this kind of the chipboards with a layer of melamine on the one hand or two respects provides a solid scratch-resistant surface and keeps the wood for long periods. It is used for many purposes and it is also durable for a long time, Nicole et. al (2010).

Nourbakhsh (2010) said that the demand for composite wood products, such as plywood, hardboard, particleboard, medium-density fiberboard (MDF), and veneer board products has recently increased substantially throughout the world. International Tropical Timber Organization (ITTO) producer countries has declined as a whole, from $52.7 \%$ of total land area in 1985 to $46.4 \%$ in 2005 in which has been due to agricultural expansion. $57 \%$ of the total production of wood-based panels are particleboard which is constantly growing at a rate of 2- 5\% annually. Particleboard consumption significantly increases each year. The demand for particleboards in the sectors of housing construction, furniture manufacturing, and interior decoration (wall and ceiling paneling) has continued to increase. On the other hand, deforestation, forest degradation, and increasing demand for wood based panels has led to a shortage of raw materials in the sector for a long time.

Chiang et al (2014) reported that with advances in technology and increase in the global population, the demand for wood in the forest product industry has grown over the years. In addition, the application of wood in new areas had also caused a significant pressure on the current standing forest resources. This has generated the necessity for people in the forest industry and scientists studying in this field to find alternative biomasses or raw materials. Alternative fibers such as agro fibres will play an important role in the wood fiber supply/demand map of the future. Physical properties like water absorption of wood are great importance, especially in the structural wood. However, wood undergoes changes in its moisture content all the time and the water absorption properties significantly affect the mechanical properties of a product.

Akers (1966) defined the particleboards as a sheet materials manufactured from small pieces of wood or other Ligno Celluloses materials (e.g. chips, flacks, shives etc.), agglomerated by use of organic binder together with one or more of the following agents: heat, pressure, moisture, etc. he added that large amount of flax are grown in various 
parts of the world for fibres or seeds production. This plant has a lingocellulosic (or woody) stem. After extracting the fibres, the remind shives are suitable for particles board manufacturing. That was found in 1947 and since that date a considerable number of flax boards have been established.

Ansell (2015) stated that particleboard (call also, Chipboard) is composed of particles and thin slivers of wood which is made by cutting the wood feedstock. The characteristics of chipboard are low costs, high thickness and the capability to manufacture large dimension boards. In 1942, a Swiss inventor used timber which was not suitable for manufacturing plywood to produce chipboard with the commercial name NOVOPAN (NOVO = new and PAN = panel). At about the same time, the German inventor Max Himmelheber developed a machine for making particles and succeeded in mass producing chipboard called Homogenholz. Hammer Milles are used for wood waste milling. The milled particles are classified from small to large by screening. Chipboard usually has a three layers' structure. Where the surface layer contains small chips and the core layer is comprised of large chips. The surface layers must be smooth for bonding on films and painting.

Ali et al (2014) stat the physical and mechanical properties including moisture content, internal bond (IB) strength, thickness swelling (TS), water absorption (WA) are used to characterize the manufactured particleboards. They added that Gum Arabic was used as a binder for fabrication of particleboards. The Gum Arabic bonded particleboards results in smoother surface, more rigid texture and better internal bonding strength compared to binderless particleboards made without using any adhesive.

Hanifi et al (2012) reported that due the rapid energy consumption many studies have been done on alternative energy generation methods. In this sense, insulation has an important place from the point of energy saving. Energy loss can be minimized by insulation technologies. The thermal conductivities, sound insulations, and bending strength of chipboards were studied in this work. It was resulted that the usage of cotton wastes and fly ash had a positive effect on the engineering properties of chipboards. It was provided that light weight constriction materials 
produced with cotton wastes, fly ash and epoxy resin could be used for getting better thermal and sound insulation results.

Biswas et al (2011) reported that development of value added products from unutilized woody or non-woody material can play a vital role in economic development of any country. Particle boards (12mm thickness) were made with $3.5 \mathrm{~N} / \mathrm{mm}^{2}$ applying pressure at $140{ }^{0} \mathrm{C}$ press temperature. Urea formaldehyde glue was used as a binder. The panels were tested to determine bending strength, modulus of elasticity, tensile strength, thickness swelling and water absorption.

Aras et al (2015) said that wood based composites, such as particleboards (PB), medium density fibreboards (MDF), plywood and wood plastic composites (WPC) are wide products used in the buildings, construction industry and many consumer products. Particleboards has become one of the most popular wood based composite materials for decoration and making furniture. It has good thermal and sound absorption properties, processing performance and low density.

Paiva et al (2012) mentioned that several authors proposed using different agricultural products such as bagasse, straw, corn stalks, cotton stalks, kenaf, rice straw, rice husk, sunflower hulls and stalk, banana stalks and bamboo for processing particleboards, hardboards and fiberboards, and focusing in their thermal insulation capacity.

Radosavljevie et al (2008) mentioned that fiberboards could be applies in the furniture, automotive and construction industries. They are high quality due to great strength of the plant fibers compared to congenial wood fibers. They added that the mixing of the fibrous materials with binder is optimized. Selection of natural binders should either be cheap or ecological, renewable and environmentally friendly but slightly harder to apply, form weaker bonds and usually are not water resistance.

Dunky (1998) said that Urea-formaldehyde (UF) resin is another member of the amino family (as is melamine) and was developed in 1929. Like melamine, it is a very hard, scratch-resistant material with good chemical resistance, good electrical qualities and heat resistance up to 170 degrees. Urea-Formaldehyde resins are formed by the condensation reaction of formaldehyde $[\mathrm{HCHO}]$ and urea $\left[\mathrm{CO}\left(\mathrm{NH}_{2}\right)_{2}\right]$. These thermoset resins are clear water-white syrups or white powered materials which can be 
dispersed in water to form colorless syrups. Urea-formaldehyde (UF) resins are the most important type of adhesive resins for the production of wood based panels. They convince by their high reactivity and good performance in the production and by their low price,

Ahamad, T. and Alshehri S. (2014) reported that Urea-formaldehyde (UF) resin is a major commercial adhesive, especially within the forest product industry. Approximately one million metric tons of UF resin are produced annually and more than $70 \%$ of this resin is used by the wood industries as an adhesive for bonding particleboard, medium density fiberboard, hardwood plywood and as a laminating adhesive for bonding due to its several strong positive aspects such as very low cost, nonflammable, very rapid cure rate, and a light colour.

\section{MATERIALS AND METHODS}

This work was done in the thin particleboard factory, Tanta flax and oils Company, Meet Hebaish El Bahria, Tanta, El Gharbia Governorate, Egypt.

\subsection{Materials}

Flax shives, citrus branches and urea formaldehyde resin were used to produce the particleboards of this work.

\subsubsection{Flax shives}

After extracting the flax fibres, the shives were transported to the thin particleboard factory to be prepared for processing.

\subsubsection{Citrus branches}

Citrus branches used in this work were supplied also to the company by the contractors. It was the output of citrus trees pruning.

\subsubsection{Urea Formaldehyde}

The used urea Formaldehyde in this work was supplied from the urea Formaldehyde factory which belonged also to Tanta flax and oils Company. It was added in a ratio of $9-10 \%$

\subsection{Methods}

\subsubsection{Milling}

The shives milled by a hammer mill and sieved. The small particles collected in a container and the big one collected in another container. 


\subsubsection{Processing}

The Dried particles of (Flax - citrus) shives were mixed together in a ratio of 1-1. Then they were blended with UF resin in a rotating drum type mixer fitted with a pneumatic spray gun. Based on oven dry particle weight 9\% UF resin was applied. No wax or any other additives were applied for panel manufacturing.

A layer of $5 \mathrm{~cm}$ of the small shives was uniformly distributed on the stage of the press machine. Then another layer of the big shives was also distributed in the same way exactly over the former layer. Then the last layer of the small shives was also distributed in the same way.

\subsubsection{Pressing}

The hydraulic press machine starts to press the distributed shives. The pressing process was under about $3.14 \mathrm{MPa} / \mathrm{cm}^{2}, 170$ press temperature and 7 min. press time. The produced boards transported to crop the edges and then stacked above each other. It is transported after that to be stored. Fig. (1) shows the press machine. It is a German press machine from the G. Siempelkamp GmbH ,Krefeld - Germany.

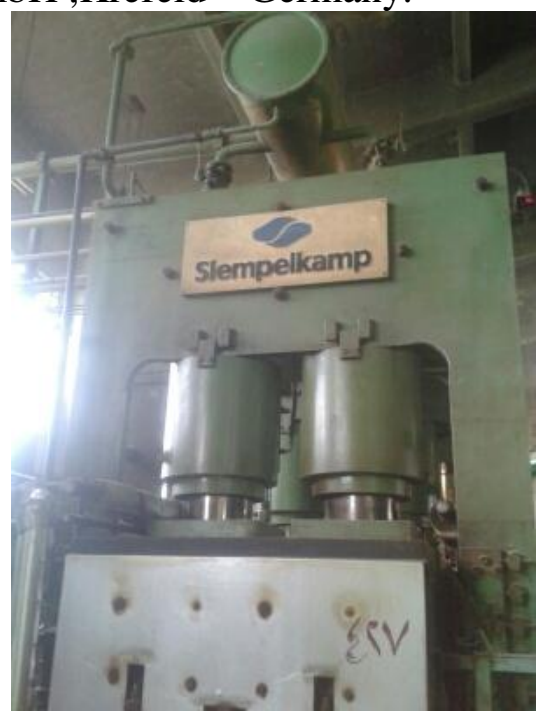

Fig. 1 the boards press machine in Tanta flax and oils Company

\subsubsection{Moisture Content}

A sample of $100 \mathrm{gm}$ weight then put in a ventilated oven at $105{ }^{\circ} \mathrm{C}$ for 24 hours. The moisture content was calculated using the following standard equation (1) of (Wernecke and Wernecke, 2014). 


$$
\text { M.C. }=\frac{S B-S A}{S B} \times 100 \%(\text { Wet base })
$$

Where:

$$
\begin{aligned}
& \text { SB = Sample weight before drying }(\mathrm{g}) . \\
& \text { SA }=\text { Sample weight after drying }(\mathrm{g}) .
\end{aligned}
$$

\subsubsection{Density}

The density is an indicator of storage, transportation, space and cost of boards. The bulk density of the boards was calculated using Eq. (2) with the sample weight and the measured volume. The volume was determined by the cross sectional area and variable thickness of the boards.

$$
\rho \mathrm{b}=\frac{\mathrm{W}}{\mathrm{L} \times B \times \mathrm{T}}
$$

$$
\begin{array}{ll}
\rho_{\mathrm{b}} \text { density of boards } & \left(\mathrm{kgm}^{-3}\right) \\
\mathrm{W}=\text { weight of the boards } & (\mathrm{kg}) \\
\mathrm{B}=\text { width of the boards } & (\mathrm{mm}) \\
\mathrm{L}=\text { length of the boards } & (\mathrm{mm}) \\
\mathrm{T}=\text { thickness of the boards } & (\mathrm{mm})
\end{array}
$$

\subsubsection{Water absorption}

The absorbed water of the samples was calculated as percentages. The board's samples were soaked in water for 24 hours. The water absorption rate increased with immersion time of samples. The following equation (3) according to (Filoh et al, 2011) was used:

$$
\mathrm{A}(\%)=\frac{M 1-M 2}{M 2} \times 100
$$

Where: $M 2$ : is the weight before the weight and $M 1$ is weight after 24 hours.

\subsubsection{Swelling thickness}

The Swelling thickness of the samples was calculated as percentages. The board's samples were soaked in water for 24 hours. The Swelling thickness rate increased with immersion time of samples. The following equation (4) according to Filoh et al (2011) was also used:

$$
\mathrm{G}(\%)=\frac{A 1-A 2}{A 2} \times 100
$$

Where: $A 2$ : is the weight before the weight and $A 1$ is weight after 24 hours. 


\subsubsection{Internal bond strength}

Internal bond strength of the particleboards is tested in a variety of ways, all of which gauge the amount of force needed to test the sample. In this test, the sample is sandwiched between and adhered to two metal plates. A force is applied at right angles to the sample, and the force required to pull the sample apart is recorded in. Fig. 2 show the internal bond stress test machine used in this work.

The internal bond stress machine is a German machine from the Factories - Otto Wolpert Werke GmbH - Ludwigshafen Germany. The machine was manufactured in year 1969.

\subsubsection{Modulus of rupture}

Modulus of rupture reflects the maximum load-carrying capacity of a member in bending and is proportional to maximum moment borne by the specimen. Modulus of rupture is an accepted criterion of strength, although it is not a true stress because it is computed formula is valid only to the elastic limit.

MOR is expressed in $\left(\mathrm{Kg} / \mathrm{cm}^{2}\right)$ or $(\mathrm{MPa})$. This number is given for wood that has been dried to12\% moisture content, unless otherwise noted. The test machine is presented in Fig 2.

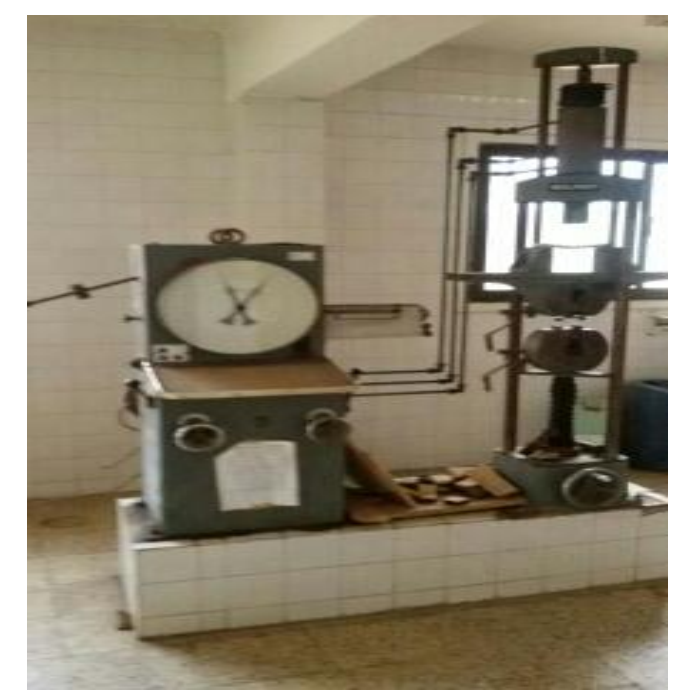

Fig. 2 the internal bond strength test machine in Tanta flax and oils Company 


\section{RESULTS AND DISCUSSION}

To compare between flax and citrus boards, the physical and mechanical properties of the both were studies. 8 replicates were made to insure the results.

\subsection{The physical properties}

The physical properties of the boards studied in this work included its moisture content (MC), density (D), water absorption (WA) and thickness swelling (ST).

\subsubsection{Moisture Content}

Most stored products are influenced by the relative humidity of the atmosphere. From the moisture content equilibrium of product 'safe', storage moisture content can be stipulated. Timber is normally dried down to about $8-10 \%$ moisture content but it will quickly reabsorb moisture if it's stored badly.

The moisture content of the particle used in this work was initially measured. Its value for the open air dried Flax shives after milling was $10.75 \%$ while it was $11.2 \%$ for citrus particles as presented in Fig 1.

\subsubsection{Density of the boards}

Density is an important physical characteristic of matter. It increases either with increasing mass or with decreasing volume. Objects with higher density are invariably heavier than low-density objects of similar appearance. This increased weight has some benefits. In our case the densities 'of particleboards made from flax shives and citrus shives were determined. The average density value of the flax boards was lower in about $8.8 \%$. Its $650 \mathrm{~kg} / \mathrm{m}^{2}$ on the other hand it recorded $713 \mathrm{~kg} / \mathrm{m}^{2}$ for citrus shives. It was due to the light weight of flax shives than the woody shives of the citrus.

\subsubsection{Water absorption}

Water seems to be a factor that affects practically all materials exposed to exterior conditions. Water is present everywhere, and even on dry sunny days there is long periods of heavy dew formation during the night, from early evening to the late morning. It is expected that water may also affect the performance and the properties of particleboards including mechanical properties, dimensional and stability. For these reasons water absorption has become prime interest in the research. 
The absorbed water of the samples was calculated as percentages. The water absorption rates were calculated according the equation of Filoh et al (2011). The results showed that the average water absorbing ratio of the citrus particles board was $42.2 \%$ while it was $83.8 \%$ for flax boards. It is clear that the citrus boards absorb water $50 \%$ lower than the flax one. That is due to the structure of the both the plants. The results are presented in Fig. 1.

\subsubsection{Swelling thickness}

Swelling is defined as increase in size or volume as a result of internal pressure or expands. The results presented in fig. (3) showed that, on the average, the swelling in thickness values of the panels produced from citrus particles are superior to those produced from flax particles within a $24 \mathrm{~h}$ period swelling thickness test. It can be noted for the panels produced from flax particles has an average value of $14.05 \%$ while it was $7.12 \%$ for the panels produced from citrus particles. The panels produced from flax particles revealed to absorb about 50\% more water than the panels made from citrus particles.

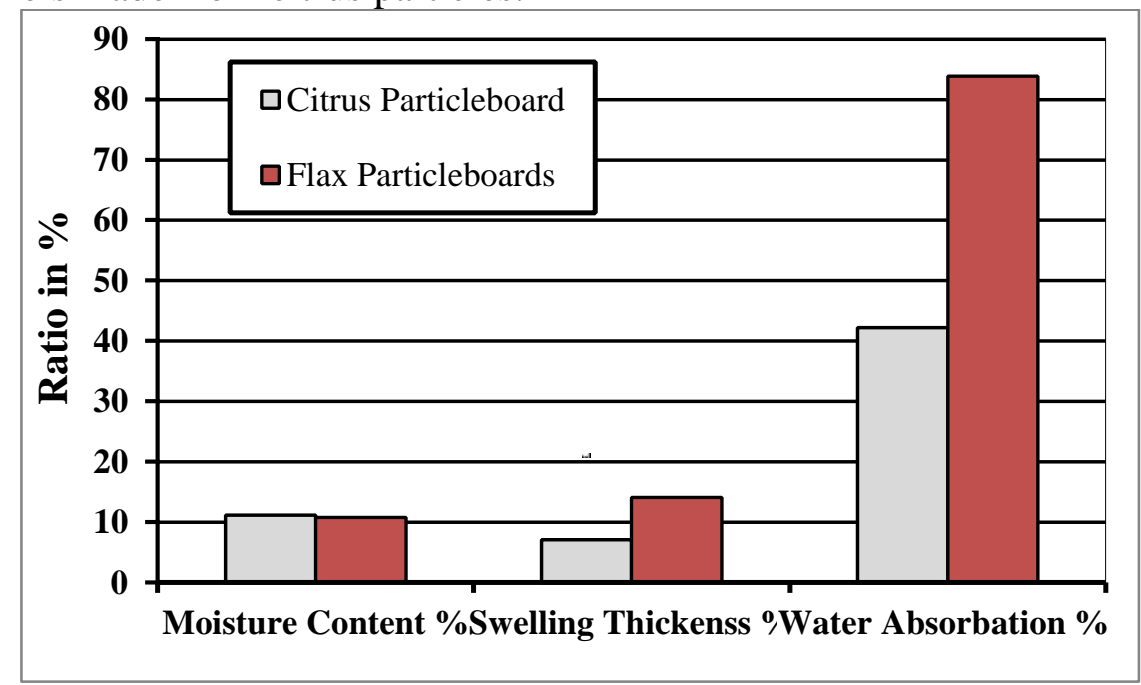

Fig. 3 The Effect of the Process Material on the Physical properties on the Particleboards

\subsection{The Mechanical properties}

The mechanical properties of the boards studied in this work included the internal bond strength (IB) and modulus of rupture (MOR). 


\subsubsection{Internal bond strength}

Particleboard fiberboard and chipboard are engineered materials made by gluing wood chips or wood particles together with an adhesive under high pressure. Increased use of these materials has resulted in the need for more stringent testing to determine their strength properties. One of these tests is the tensile strength perpendicular to surface test, also known as the internal bond strength test. This test is also commonly used as a fundamental measure of the adhesive performance in wood composites and covers the determination of tensile strength properties of these boards or adhesive bonds in wood.

In this work, Modulus of Rupture, frequently that is because of the structure of the citrus stem rich with lignocelluloses materials which make the stem very strong. The value of internal bond strength was 9.32 $\mathrm{Kg} / \mathrm{cm}^{2}$ for the panels produced with citrus particles. It was $4.46 \mathrm{Kg} / \mathrm{cm}^{2}$ that panels produced with flax particles as presented in fig. 4 .

\subsubsection{Modulus of rupture}

Modulus of Rupture, frequently abbreviated as MOR, (sometimes referred to as bending strength), is a measure of a specimen's strength before rupture. It can be used to determine a wood species' overall strength; unlike the modulus of elasticity, which measures the wood's deflection, but not its ultimate strength.

(It is to say, some species of wood will bow under stress, but not easily break).

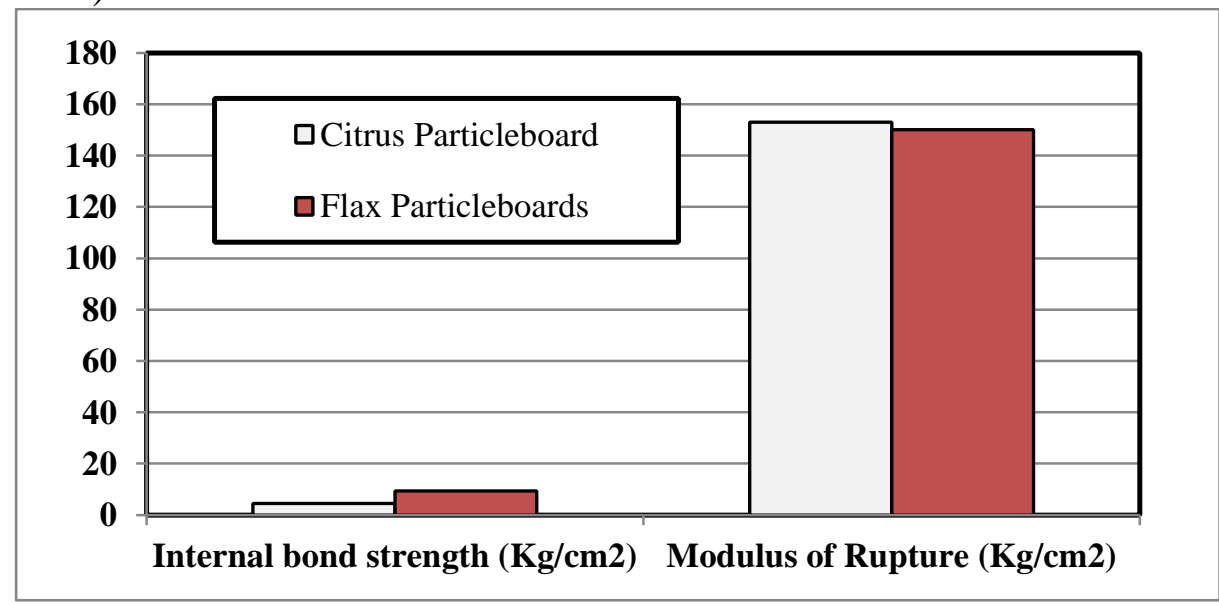

Fig.4 The Effect of the Process Material on the Mechanical Properties on the Particleboards 
The average values of the results presented in fig (4) showed that, values of the panels produced with citrus particles differ not too much than those produced with flax particles. Its average value was $150 \mathrm{Kg} / \mathrm{Cm}^{2}$ for panels produced from flax particles. On the other hand, it was 153 $\mathrm{Kg} / \mathrm{Cm}^{2}$ for the panels produced from citrus particles.

\section{CONCLUSION}

Particleboard is a high grade, composite material made from recycled wood fibres and resin. Because the retreating of the cultivated area of flax to about $10 \%$ in the last decade there was a necessity to find a substitute raw material for flax shives which are used in particleboard production. In this work, the citrus shives was used a substitute material for flax. The results of the physical properties showed that, the average density value of the flax boards was lower in about $8.8 \%$ than that from woody shives of the citrus. The results showed also that, the average water absorbing ratio of the citrus particles board was absorbing water 50\% lower than the flax one. In the other hand, the mechanical properties showed that the average values of modulus of Rupture of the panels produced with mandarin particles differ not too much than those produced with flax particles. Its average value was $150 \mathrm{Kg} / \mathrm{Cm}^{2}$ for panels produced with flax particles and it was $153 \mathrm{Kg} / \mathrm{Cm}^{2}$ for the panels produced from citrus particles. The value of internal bond strength was double the value that for panels produced from flax particles. It can be summarized that citrus shives can be used to produce particleboards with good properties.

\section{ACKNOWLEDGMENTS}

The author desires to express his deep thanks, personal gratitude and sincere appreciation to Dr. Rageh El Ngar the head of the quality Laboratory, Tanta Flax and Oil Company for his extremely kind assistance to do this work. I wish him happy and healthy life.

Special thanks also to the Company director and the staff members of the company management for the facilities provided for this work.

\section{REFERENCES}

Ahamad, T. and Alshehri S. (2014). Thermal degradation and evolved gas analysis: A polymeric blend of urea formaldehyde (UF) and 
epoxy (DGEBA) resin. Arabian Journal of Chemistry (2014) 7, $1140-1147$.

Akers, L. (1966) Particle board and hardboard. Pergamom Press Ltd., London. Pp 3-20.

Ali A., R. Hashim, S. Bauk, S. Kandaiya and E. Tousi (2014). Fabrication and characterization of Gum Arabic Bonded Rhizophora Spp. Particleboards. Materials and Design, Volume 60, August 2014, Pp. 108 -115. ELsevier Publischer.

Ansell, M. (2015). Wood Composite. Wood head Publishing, Pp. 106$108,2015$.

Aras U., H. Kalayokioglu, H. Yel and G. Bitek (2015). Effect of Ammonium Nitrate on Physico-Mechanical Properties and Formaldehyde Contents of Particleboard. Social and Behavioral Sciences 195 (2015) Pp. 2130-2134.

Biswas, D., S. Bose, and M. Hossain (2011). Physical and Mechanical Properties of Urea Formaldehyde - Bended Particleboards made from bamboo wastes. International Journal of Adhesion and Adhesives. Volume 31, Issue 2. March 2011, Pp 84 - 87.

Chiang, T., M. Osman and S. Hamdan (2014). Water Absorption and Thickness Swelling Behavior of Sago Particles Urea Formaldehyde Particleboard. International Journal of Science and Research (IJSR) Volume 3 Issue, December 2014 Pp: 1375-1379.

Dunky, M. (1998). Urea-formaldehyde (UF) adhesive resins for wood. International Journal of Adhesion and Adhesives. Volume 18, Issue 2, March 1998, Pages 95-107.

Filoh, R., L. Mendes, K. Novack. L Aprelini and V. Botaro. Hypred Chipboard Panels Based on Sugarcane Bagasse, Urea Formaldehyde and Melamine Formaldehyde Resin. Industreal Crop and Products, Volume 33 (2011) 369 -373.

Hanifi, B., R. Gemci, A. Kucukonder and H. Solka (2012). Investigating sound insulation, thermal conductivity and radioactivity of chipboards produced with cotton wastes, fly ash and barite. Construction and Building Materials. Volume 30, May 2012, Pp. $812-832$.

Nourbakhsh, A. (2010). Mechanical and Thickness Swelling of Particleboard Composites Made from Three-Year-Old Poplar Clones. Journal of Reinforced Plastics and composites, Vol. 29, No. 4/2010. 
Paiva, A., S. Pereira, A. Sa, D. Cruz, H. Varum, and J. Pinto (2012).

A Contribution to the thermal insulation performance characterization of corn cob particleboards. Energy and Buildings. 45 (2012) 274-279.

Nady, S. and G. Roland (2008). Dual Purpose Flax (Linum Ustiatissimum) Improvement using Anatomical and Molecular Approaches. The 2008 International Conference on Flax \& other Bast plants, July 21: 23.Saskatoon Kanda.

Nicole, S., Zhiyong, C. and C. Charles (2010) Wood Hand Book, Wood as Engineering Material, Chapter 11. United States Department of Agricultural.

Radosavljevie, L., R. Pecenka and F. Fuerll (2008). Natural Binder for Fibreboard Made of Hemp. International Conference on Flax and Other Bast Plants. SASKATOON, CANADA, 21-23 JULY 2008.

Wernecke, R. and J. Wernecke (2014). Industrial Moisture and Humidity Measurement. Wiley-VGH Verlag GmbH, Weinheim, Germany.

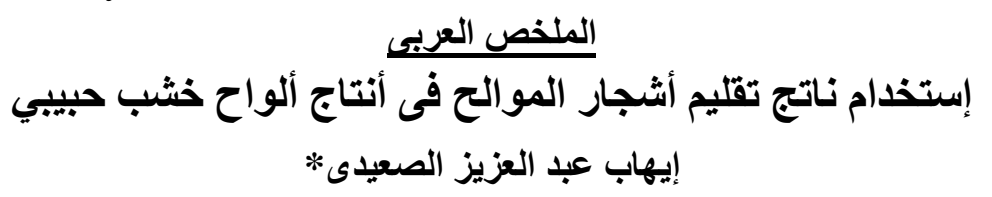

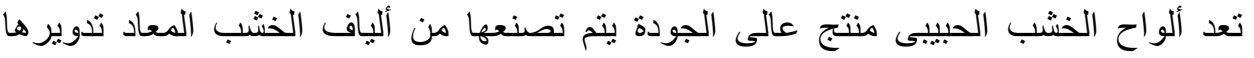

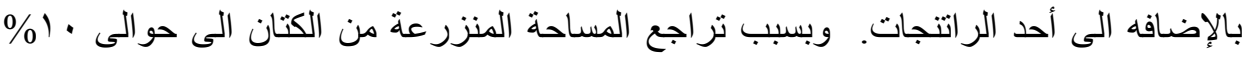

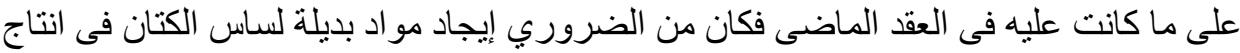

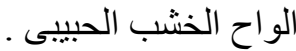

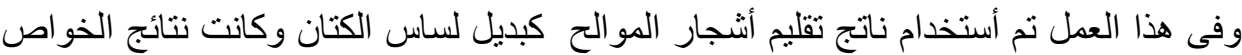

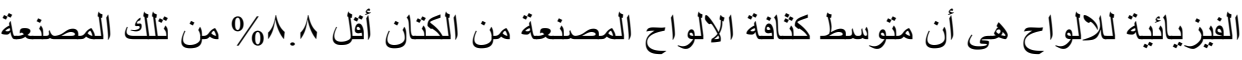

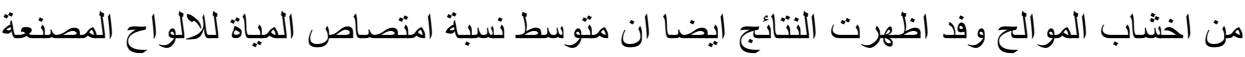
من اخشاب المو الح أقل ـ0\% من تلإلك المصنعة من ساس الكتان .

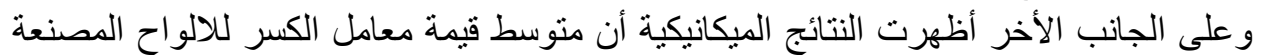

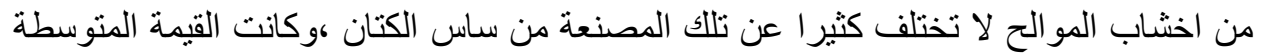

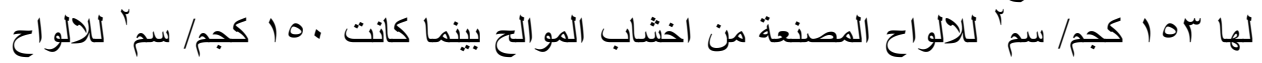

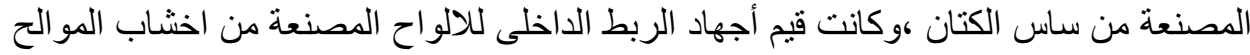

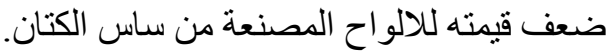

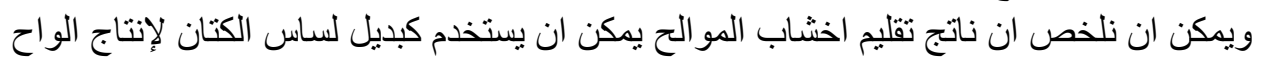
من الخشب الحبيبى ذات موصفات جيدة. *مدرس بقسم الهندسة الزراعية كلية الزراعة - جامعة المنوفية. 